\title{
Pumpkin (Cucurbita moschata) breeding priorities based on a survey among Puerto Rican consumers ${ }^{1,2}$
}

\author{
Manuel E. Carbonell,s Linda Wessel-Beaver, ${ }^{4}$ Felicita Varela ${ }^{5}$ \\ and Brunilda Lucianos
}

\begin{abstract}
A sample survey of consumer preferences was conducted in order to determine what characteristics should be given highest priority in a pumpkin (Cucurbita moschata) breeding program for Puerto Rico. A tofal of $\mathbf{5 2 7}$ people from all regions of the island participated in the survey. Very few preference differences were found due to regions, age groups, sex, or frequency of consumption. Pulp color was the most important characteristic considered when purchasing pumpkin. Most participants preferred an orange-yellow internal color. Skin color was also an important consideration. Respondents strongly preferred a 'pinta' or piebald pumpkin skin. Fruit size was important to many surveyed: most preferred a medium size fruit. Most respondents said they bought pieces rather than whole fruit. Skin fype and fruit shape were not important considerations for most respondents. In addition to selection for increased yield, a pumpkin breeding program for Puerto Rico should emphasize selection of genotypes with deep orange-yellow pulp, a 'pinta' skin color and medium-sized fruits.
\end{abstract}

\section{RESUMEN \\ Preferencias en la compra de calabaza entre los consumidores puertorriqueños}

En cuatro actividades públicas en Puerto Rico se efectuó una encuesta sobre las preferencias del consumidor al comprar calabaza. El objetiva de la encuesta fue deferminar qué características debian tener mayor prioridad en un programa de mejoramiento de la calabaza. Se entrevistaron 527 personas de todas las regiones de la isla. El color de la pulpa fue la característica de mayor importancia; los consumidores prefirieron el color anaranjado-amarillo. El color de la cáscara fue una característica determinante. La cáscara color pinta (verde-blanca) fue altamente preferida por los participantes. El tamaño de la fruta fue importante para muchos, ya que prefirieron una calabaza de tamaño mediano. La mayoría de los participantes dijeron que preferían comprar pedazos de calabaza y no frutas enteras. El tipo de cáscara y la forma del fruto no fueron características

'Manuseript submitted to Editorial Board 14 July 1988.

"This research was supported by the U.S. Department of Agriculture under CSRS Special Grant No. 86-CRSR-2-2810 managed by the Caribbean Basin Advisory Group (CBAG). A portion of this research was submitted by the senior author in partial fulfillment of the requirement for the M.S. degree at the University of Puerto Rico.

${ }^{3}$ Graduate student, Department of Horticulture.

Associate Professor, Department of Agronomy and Soils.

${ }^{5}$ Research Assistant, Department of Horticulture. 
importantes para la mayoría de los participantes. Hubo muy poca diferencia en preferencia entre las diferentes regiones de la isla, los diferentes grupos de edad y sexo y la frecuencia de consumo. Un programa para desarrollar variedades de calabaza para los consumidores puertorriqueños debe seleccionar genotipos con una pulpa de color anaranjado-amarillo, una cáscara pinta y frutos medianos, además de mayor rendimiento.

\section{INTRODUCTION}

The native pumpkin [Cucurbita moschata (Duch) Duch ex Poir.], or "calabaza" as it is known in Spanish, has been a principal vegetable in the Puerto Rican diet since pre-Columbian times. At present, Puerto Rico is nearly self-sufficient in pumpkin production. Imports vary from 5 to 10 percent of all marketed pumpkin (4). In 1986-87 per capita fresh consumption was $14.3 \mathrm{lb}$ of fresh pumpkin (4).

In 1984, Unander (5) conducted a survey of six island supermarket purchasing agents and food processors, and found that five out of six preferred a medium vs. small or large fruits. There were no marked preferences for external color, but round and flat shapes were most desired. Internal color preference was divided between "deep orange" and "deep yellow" over all lighter shades. A similar survey was performed with 27 UPR-Agricultural Experiment Station personnel in 1985. Responses were similar to those of the 1984 survey except that size preferences were divided between small and medium fruit (5). Both surveys had few participants and were limited in scope.

C. moschata exhibits a large amount of genetic variability for traits such as fruit size, skin color, pulp color and pulp thickness. Effective use of this variability depends on identifying the relative importance of traits such as those mentioned above. The objectives of the present survey were to identify fruit characteristics most preferred by the consumer, and to determine relative importance of those characteristics when breeding new pumpkin varieties for Puerto Rico.

\section{MATERIALS AND METHODS}

A sample survey of consumer preferences using the quota method (6) was conducted at four public events in different parts of Puerto Rico in 1987 and 1988. These were the Mango Festival (Juana Díaz, 234 participants), University of Puerto Rico, Mayagüez Open House (41 participants), the Caguas Agricultural Fair (122 participants), and the Lace Festival (Isabela, 130 participants).

Respondents completed a prepared survey form. Questions dealt with visual and physical pumpkin features, frequency of consumption and characteristics that potentially affect consumer purchase. Photographs were used to identify pulp colors, fruit shapes and skin colors.

Pulp colors in the photographs corresponded to plate number 10, code numbers 2I (very light yellow), 4K (light yellow), 9I (orange-yellow) and 


$$
\text { J. Agric. Univ. P.R. VoL. 74, No. 3, JULY, } 1990
$$

12L (dark orange) in Maerz and Paul (3). Fruit shapes are diagrammed in figure 1. Demographic information was also requested (table 1 and the following tabulation).

Frequency of Consumption
Daily
3 to 6 times weekly
1 to 2 times weekly
Less than once weekly
No response
$\quad$ Total

Results were tabulated to obtain frequency tables for each question. A chi-square test of independence was used to determine possible differences in response due to age group, sex, region of Puerto Rico, or frequency of consumption. Respondents from outside Puerto Rico were eliminated from the analyses.

\section{RESULTS AND DISCUSSION}

The quota method used in this survey cannot be regarded as the equivalent of random sampling (6). Since some danger of bias is always present, results from this type of survey cannot always be generalized to the population as a whole. However, precise estimates of consumer
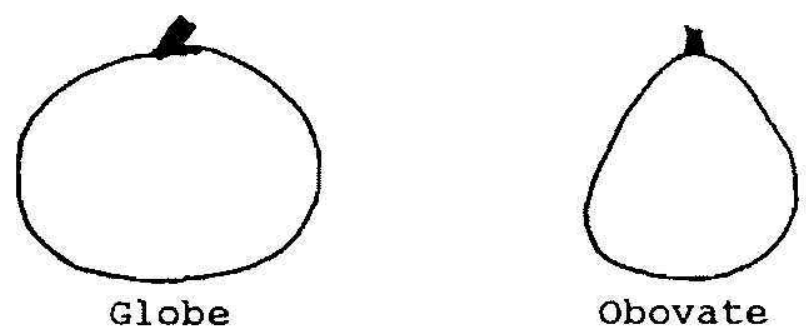

obovate

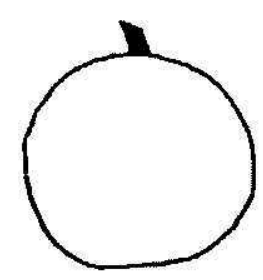

Round

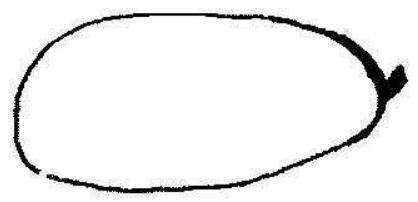

Melon

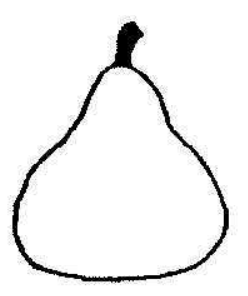

Pear

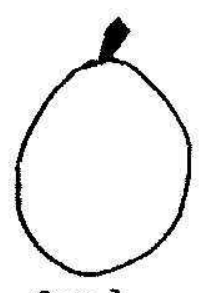

oval

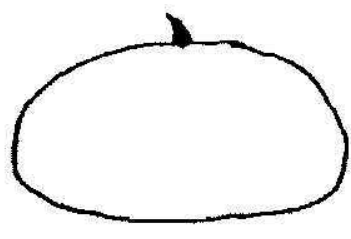

Flat

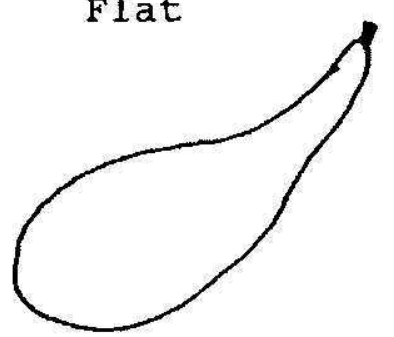

Gourd

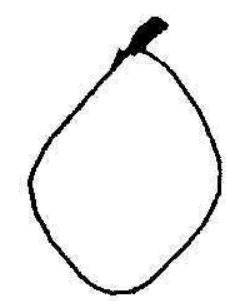

Elliptic

FiG. 1.-Pumpkin shapes included in preference survey. 
TABLE 1.-Distribution of pumplin preference survey respondents by region in Puerto Rico, age group, and sex:

\begin{tabular}{lrr}
\hline Demographic Group & Number & Percent \\
\hline Region & & \\
\hline North & 152 & $29 \%$ \\
South & 144 & $27 \%$ \\
East & 28 & $5 \%$ \\
West & 140 & $27 \%$ \\
Central & 57 & $11 \%$ \\
No response & 6 & $1 \%$ \\
Total & 527 & $100 \%$ \\
Age Group & & \\
18 to 25 & 120 & $23 \%$ \\
25 to 40 & 166 & $31 \%$ \\
41 to 55 & 128 & $24 \%$ \\
Over 55 & 78 & $15 \%$ \\
No response & 35 & $7 \%$ \\
Total & 527 & $100 \%$ \\
Sex & & \\
Male & & $42 \%$ \\
Female & 222 & $56 \%$ \\
No response & 293 & $2 \%$ \\
Total & 12 & $100 \%$ \\
\hline
\end{tabular}

preferences, such as those from a completely random survey, were not required to meet our survey objectives. We were interested only in determining relative importance of various pumpkin traits in a breeding program. The relative importance of characteristics in this survey would remain the same even if the bias were three times greater than indicated by the standard deviations observed in this study (tables 2, 3, 4 and 5).

Compared with the actual population distribution of the island $(1,2)$, the western and southern parts of the island were somewhat over-represented and the northern part of the island was slightly under-represented in our survey (table 1). The percentage of respondents from the central and eastem part of the island was similar to the actual population distribution.

The age group distribution in our survey closely follows the actual age group distribution in Puerto Rico for those 18 years or older (table 1). One exception was that the over-55 group was under-represented in our survey. About $24 \%$ of the population 18 years of age or older is over 55 (2).

- Female respondents were somewhat over represented in our survey (table 1). The number of males answering the survey was significantly lower than the number of females. Women were generally more willing to answer our survey. When couples visited our booth, the husband 
would often ask the wife to answer the survey since she usually did the shopping and meal preparation.

A chi-square test of homogeneity was used to test whether preferences varied depending on region, age group, sex, or frequency of consumption. We expected to see some differences in preferences between, for example, one region of the island and another. However, we found very few differences from one group to the next.

Frequency of consumption was least likely to influence preferences. Daily users of pumpkin were not particular about skin texture. As pumpkin use decreased, preference for smooth skin increased. There were small regional differences for skin and pulp color. Respondents from western Puerto Rico chose pale yellow pulp color and green mottled skin color more often than those from other regions. However, the strong preference for orange-yellow or dark orange pulp color and pinta skin color was consistent among all regions.

Preferences for skin thickness and hardness were dependent on age group. Respondents in the older age groups were more likely to prefer thick rather than thin skinned fruits. They were also more likely to prefer easy to penetrate skin. Some differences were also seen among age groups in terms of characteristics that most influenced their buying habits. Younger respondents felt that size was a more important purchase consideration than older respondents. Older respondents were more likely to weigh all factors. They were especially likely to give more consideration to skin type than were younger respondents.

The sex of a respondent also influenced preferences. Women were more likely to have no preference as to skin texture and shape. They were also more likely to choose dark orange pulp color whereas men more often chose yellow pulp color. However, both sexes preferred orange-yellow pulp color over all others. Women preferred pieces more often than men.

Because only a few preference differences among groups were found, responses were combined. The authors feel the survey adequately represents consumer preferences in Puerto Rico for the purpose of defining breeding priorities.

About two-thirds of the respondents used pumpkin at least once a week as mentioned before. One in 10 persons said they consumed pumpkin every day. This finding confirms the importance of pumpkin in the Puerto Rican diet. Actual use is probably greater since pumpkin is often used in less obvious ways, such as in soups and sauces.

More than three-fourths of those taking the survey preferred an orange-yellow to dark orange pulp color (table 2). Of this group more than two-thirds preferred an orange-yellow rather than dark orange pulp. 
TABLE 2.-PUmpkin pulp color, shape, and skin color preferences among survey respondents $(n=527)$

\begin{tabular}{lrr}
\hline Preference & Number & Percent' \pm S.D. ${ }^{2}$ \\
\hline Pulp Color & & \\
\hline Very light yellow & 38 & $7 \pm 1.1$ \\
Light yellow & 61 & $12 \pm 1.4$ \\
Orange-yellow & 275 & $52 \pm 2.2$ \\
Dark orange & 138 & $26 \pm 1.9$ \\
No preference & 40 & $8 \pm 1.2$ \\
Shape & & \\
Globe & 221 & $42 \pm 2.1$ \\
Obovate & 16 & $3 \pm 0.7$ \\
Flat (Borinquen-type) & 174 & $33 \pm 2.1$ \\
Round & 111 & $21 \pm 1.8$ \\
Pear & 56 & $11 \pm 1.4$ \\
Gourd & 15 & $4 \pm 1.0^{3}$ \\
Melon & 3 & $2 \pm 1.2^{4}$ \\
Oval or elliptic & 14 & $5 \pm 1.3^{5}$ \\
No preference & 58 & $11 \pm 1.4$ \\
Skin Color & & \\
Dark green & & $12 \pm 1.4$ \\
Dark pinta & 61 & $29 \pm 2.0$ \\
Pinta & 152 & $54 \pm 2.2$ \\
Light pinta & 287 & $8 \pm 1.2$ \\
Pale orange & 42 & $8 \pm 1.2$ \\
Mottled & 43 & $5 \pm 1.0$ \\
No preference & 25 & $10 \pm 1.3$ \\
\hline
\end{tabular}

'Total is greater than $100 \%$ since respondents could choose more than one pulp color, shape, or skin color.

"Standard deviation.

:Shape was included in the Fortuna, Mayagüez and Caguas surveys $(n=398)$.

"Shape was included only in the Isabela survey $(n=129)$.

${ }^{5}$ Shape was included only in Fortuna and Mayagüez surveys $(n=275)$.

Globe- and flat-shaped fruits were strongly preferred (table 2). The common cultivar 'Borinquen' has a flat shape (although other forms such as pear-shape may be found because of seed impurity). Round and pearshaped fruit were fairly well accepted, whereas other shapes had low acceptance. One out of 10 respondents had no fruit shape preference.

A marked preference was shown for 'pinta' and dark green 'pinta' skin color (table 2). Pinta is the Spanish word that describes a fruit that is piebald or with light and dark coloring. Other colors were much less accepted. We expected that dark green fruit would have had greater acceptance since it is the color of the true Borinquen variety. Our results might have been biased since the fruit in the photograph used to represent this color had an unpopular shape. 
TABLE 3.-Respondents' preference for pumpkin size and whether whole pumptins or pieces were preferred $d^{2}$

\begin{tabular}{lrr}
\hline Preference & Number & Percent \pm S.D. \\
\hline Size & 58 & \\
Small (8 lb. or less) & 109 & $23 \pm 2.7$ \\
Medium (8 to 15 lb.) & 21 & $43 \pm 3.1$ \\
Large (over 15 lb.) & 64 & $8 \pm 1.7$ \\
No preference & & $26 \pm 2.8$ \\
Whole vs. Pieces & 62 & $25 \pm 2.7$ \\
Whole fruit & 114 & $45 \pm 3.1$ \\
In pieces & 75 & $29 \pm 2.9$ \\
No preference & \\
\hline
\end{tabular}

'Responses from Caguas and Isabela surveys only $(n=252)$.

"Standard deviation.

Most people surveyed preferred to buy a medium sized pumpkin (table 3). A large portion of those surveyed (one-fourth) had no size preference, and an almost equal number preferred small fruit. Only a small percentage preferred a large fruit.

Almost twice as many respondents preferred to purchase pumpkin cut in pieces rather than as whole fruit (table 3). A large percentage of the respondents, however, had no preference. A preference for pieces may be due to the consumer's desire to see pulp color, the need for only a small amount of pumpkin at a time, or both.

In general, few strong preferences were found among respondents in terms of skin characteristics (table 4). Thin skin was preferred slightly more often than thick, although "no preference" was the most common

TABLE 4.-Skin characteristic preferences among respondents in Caguas and Isabela surveys $(n=252)$

\begin{tabular}{lcr}
\hline Preference & Number & Percent \pm S.D.' \\
\hline Skin thickness & & \\
\hline Thin & 86 & $34 \pm 3.0$ \\
Thick & 71 & $28 \pm 2.8$ \\
No preference & 95 & $38 \pm 3.1$ \\
Skin hardness & & \\
Easily punctured & 94 & $37 \pm 3.0$ \\
Difficult to puncture & 67 & $27 \pm 2.8$ \\
No preference & 91 & $36 \pm 3.0$ \\
Skin texture & & \\
Smooth & 102 & $41 \pm 3.1$ \\
Rough & 24 & $9 \pm 1.8$ \\
No preference & 126 & $50 \pm 3.2$ \\
\hline
\end{tabular}

'Standard deviation. 
TABLE 5.-Fruit characteristics that influence pumpkin purchases (in order of preference)

\begin{tabular}{lcr}
\hline Characteristic & Number & Percent' \pm S.D.' \\
\hline Pulp color & 303 & $57 \pm 2.2$ \\
Skin color & 185 & $35 \pm 2.1$ \\
Fruit size & 123 & $23 \pm 1.8$ \\
Skin type & 75 & $14 \pm 1.5$ \\
Fruit shape & 53 & $10 \pm 1.3$ \\
\hline
\end{tabular}

'Percentages do not sum up to $100 \%$ since more than one characteristic response was allowed.

${ }^{2}$ Standard deviation.

response. Easily punctured skin was preferred over difficult to puncture. On visits to island markets we often noticed whole fruits punctured hy fingernails, presumably to test internal color. Many respondents had no preference in regard to this trait. Of those respondents expressing a preference, a great majority chose smooth skinned fruit rather than rough-skinned. Half of the respondents answered that they had no preference.

As to pumpkin characteristics that most influenced purchasing decisions by consumers, more than half indicated that pulp color weighed heavily in their decision, followed by skin color and fruit size (table 5). Skin type and fruit shape played little role in their buying decisions.

The results indicate that a pumpkin breeding program should have as a priority the development of cultivars with orange-yellow or orange pulp color. Breeding for a pinta skin type could be a second priority, although dark green fruit could also be considered. Medium fruit size should also be a goal in a breeding program. Finally, a wide amount of variability would be acceptable in terms of skin type and fruit shape as long as a cultivar has good pulp color.

\section{LITERATURE CITED}

1. Anonymous, 1980. Census of Population. Vol. 1, Characteristics of the Population. Chapter A. Number of Inhabitants, part 53, Puerto Rico. (PC81-1-A53). June 1982.

2. - 1980. Census of Population. Vol. 1, Characteristics of the Population. Chapter D. Detailed Population Characteristics. September 1984.

3. Maerz, A. and M. R. Paul, 1950. Dictionary of Color. 2nd ed. McGraw Hill Book Co. Inc., N.Y.

4. Medrano, H. A., 1988. Hortalizas: Empresas Agrícolas de Puerto Rico, Situación y Perspectivas, 1986-87. Esta. Exp. Agríc., Univ. P. R.

5. Unander, D., 1986. Hatch 262, Final Report. Agric. Exp. Stn., Univ. P. R.

6. Yates, F., 1981. Sampling methods for censuses and surveys. 4th ed., MacMillan Publishing Co., Inc. New York. 